\title{
Reflection on Transitioning the Therapeutic Relationship from the Bedside to the Telephone
}

\section{Robin Pelkki}

Mount Sinai Hospital, New York, USA

*Corresponding author: Robin Pelkki, RN-BC, Mount Sinai Health System, USA, E-mail: robin.pelkki@mountsinai.org

Received date: January 09, 2018; Accepted date: February 13, 2018; Published date: February 21, 2018

Copyright: (c) 2018 Pelkki R. This is an open-access article distributed under the terms of the Creative Commons Attribution License, which permits unrestricted use, distribution, and reproduction in any medium, provided the original author and source are credited

\section{Introduction}

Communication is vital to human beings in all aspects of life and health. Clinicians must also be aware that therapeutic communication can affect both their patient's ability to heal and willingness to cooperate with plans of care. Therapeutic use of self is an additional aspect of communication in healthcare that manifests emotional engagement with patients to foster a perception of genuine participation in the patient's experience and an authentic relationship [1]. This reflection is about transferring bedside communication and assessment skills to telephonic engagement with patients transitioning care home after being discharged from the hospital.

\section{The Impact of Health Reform}

This nurse transferred a career as a graphic artist, skilled in visual communication, to bedside nursing in a busy urban hospital ten years ago. It was challenging to work as an aide while completing a nursing degree but reinforced the resolve to become a Registered Nurse, a clinician who creates value and advocacy for their patients during their time in acute care. I saw action in telemetry both as an aide and an RN, got board-certified in Cardiac Vascular nursing, and routinely cared for 6-8 acutely ill patients with multiple comorbidities during each shift. This background served well three years ago when my unit became a Rapid Evaluation and Treatment Unit (RETU), formed to respond to healthcare reform changes that endeavor to reduce readmissions. The RETU saw only patients from the ER who was not quite sick enough to be admitted but a little too sick to be discharged.

My current department is a telehealth unit dedicated to readmission reduction. Similarly to the RETU, it is a new initiative resulting from healthcare reform and the focus is also on reducing hospital readmissions [2]. Readmissions result from multiple factors:

- Poor communication between patients and hospital staff.

- Discharge planning that does not address the complete transition of care.

- No access to care or unclear source for patient needs and questions.

- Poor patient compliance or misunderstanding of medications and recommendations.

- Inability of the patient to comply with the discharge plan.

- Socioeconomic issues in the patient's home environment $[3,4]$.

Evidence-based best practices have shown that reducing readmissions calls for better discharge planning processes, transition of care plans, teach-back education practices and coaching patients on self-management. Five months ago I became a tele-nurse.

\section{Reaching Out}

Inpatient discharges are contacted within $72 \mathrm{~h}$ of discharge. Patients are informed before they leave the hospital that they will receive a phone call and asked for a preferred phone contact and time to call. The purpose of the call is to ensure that the discharge plan is successful; the patient understands the plan of care has encountered no problems with medications or durable medical equipment and has connected with community caregivers from the home.

The happy result of this program after one year's time is demonstrable reduction in hospital readmissions and a valuable source of information for quality improvement in the discharge process per covered unit [2]. My department meets regularly with each hospital to review issues-improvement is often immediate, or results in, ongoing projects. Telephoning patients has also resulted in a positive effect on HCAHPS scores [5].

A tele-nurse must connect with the patient immediately in order to be successful. The chart review familiarizes the nurse with the admission care history as well as on-going chronic conditions. A script is provided-strict adherence to its contents is stressed while conversational tone is encouraged. As anyone who has received a call from a telemarketer knows, it is easy to determine if someone is reading it off. Specific aspects include, after a greeting and introduction, an assessment of health, appetite, and mobility. The patient is requested to vocalize the reason for their hospitalization or their main diagnosis, and the signs and symptoms to watch out for. The tele-nurse ensures that all medications have been obtained, are understood and being taken as prescribed. Community health services are reviewed, durable medical equipment, and follow-up appointments are reinforced. The call concludes with the patients' assessment of the care they received while an inpatient [4].

Does that sound easy? New challenges presented themselves to me when I became a tele-nurse five months ago. Therapeutic communication is a focus on speaking, listening, focused assessment, and remote problem solving [1,6]. A good discharge is evident; the patient understands their diagnosis and plan of care [7]. A less than good discharge presents issues that must be addressed. Does the patient have new symptoms? Is their pain uncontrolled? Were they unable to get their prescribed medications? Why? Are they unable to get to their doctor's appointments? Do they not understand what was wrong and how they can help themselves going forward? Questions must be knowledgeably and professionally addressed. This nurse recalls pharmacy instruction that advised 'never give a medication if you do not know what it is' and that goes for phone calls, too! If your patient cannot walk to the taxi, they will not be able to go to their hemodialysis appointment and will end up right back in the hospital. Perhaps the home attendant has not shown up, your patient is hungry and dirty or cannot get their medication. Many patients do not 
understand that their source of care after the hospital is their primary care provider and they don't have one [2]. They may be taking a medication prescribed by another physician and did not tell the hospital caregivers about it.

Anything that can go wrong will. Patients and their caregivers become overwhelmed upon arriving home. Patient and calm coaching skills are invaluable [8]. People like to hear that they are doing a good job. After all, the patients themselves as well as each one of us are the real administrators of our own health. Patient education is a huge component of care transitions-motivation for change is highly influenced by supportive relationships [8].

\section{Evaluation and Event Handling}

Calls are carefully listened to by departmental leadership who regularly choose calls to review with the nurse [6]. It is difficult to listen to a call of your own - easy to spot the missteps and mistakes after the fact. Truth is, however, listening to yourself can make your calls more successful and more enjoyable for both you and your patient. Internalizing the script makes it easier to translate it into friendly colloquial phrases. I was pleased when my colleagues told me, "We hear the caring. We are sure the patients hear it, too" (personal converation December 14, 2017).

When I begin a call, I have found that a pleasant greeting and direct request to speak to the patient by name is best. The preceding chart review helps focus on the patient, their current health, and the goals for discharge [6,7]. The script starts with a string of sentences that can sound rote. We use our full name and title and identify the discharging hospital alpng with our department [4]. Ring a bell? Second to talk? Almost every person responds to a pleasant Good Morning or Good Afternoon. I speak slowly, introducing myself, until I can assess their ability and comprehension. They know that I want to help, I state my purpose: I am calling to review your discharge plan and make sure that all is going well for you after your recent hospital stay [4]. There are innumerable loose ends to resolve, multiple community resources to call upon, multiple EHRs to contend with, and most importantly, a patient who is still feeling not quite right who needs your help right in this instant [6].

At times the call can become overwhelming if the patient is having one or more concerning problems. Many patients have acute need to be listened to [7,9]. One good open-ended question can release a floodgate of unburdening. I have learned to tackle one issue at a time, using the script to make sure all of the necessary information is covered [6]. If a patient wants to vent I listen. I respond back with affirmation. I often apologize if they had a bad experience. I offer empathy, and, when appropriate, sympathy. Open ended questions can set a patient into a long monologue. I listen first until I can gently redirect or assure that I can help with that problem. If their issue is substantial I assure them that I will make a full report to my nurse manager and the patient experience department [9]. Calm and compassionate responses provide reassurance to an overwhelmed patient or caregiver who has just arrived back at home and is processing much information as well as the stress associated with great emotional intensity $[6,7]$.

\section{The Patients Voice}

During one call a daughter compared her experience a larger hospital with the hospital her father had just been cared for in. She said,
"The big hospital created an atmosphere of irritation and isolation. On the phone I was transferred from person to person, department to department, spent many, many minutes and hours - on the phone, and felt that my concerns meant nothing to people who were all so busy that they could not spare a moment of attention even when they were talking to me directly. This hospital was friendly and the people personable. People smiled and were pleasant - they took the time to talk to you nicely. We were made comfortable. It made us feel that things were going to be all right and, even if they weren't, that the people were going to be there for you. The positive atmosphere was healing in and of itself." -CAREGIVER BY TELEPHONE

Positivity is a great quality to cultivate in healthcare for the very purpose of relentless concentration on the patient experience [9]. The perception of caring is effortlessly manifested in a therapeutic relationship.

\section{Conclusion}

This nurse finds that telephonic work is, in some ways, more wholly patient-centered than being at the bedside. During the telephone encounter there are no interruptions as often can happen bedside. Pure concentration on one patient at a time, focusing on their needs, their questions, and their specific health concerns. It is gratifying to be able to explain or review aspects of their care or health condition that puzzle them. The patient on the phone with you is, episodically, always the center of focus. There is opportunity for service recovery in the instance of bad experience and direct emollient emotional support. Patients do thank you for listening. Patients do appreciate the time you take to explain their questions. If a patient encounter is intense, and they sometimes are, the nurse can take a few moments and refresh her outlook before contacting the next patient.

The reviews that I receive compare my efforts over time. I have an average length of call, an average number of interventions. Consistency is valued. I am patient and explain carefully. From the beginning, when it felt uncomfortable and precarious over the telephone, it now seems natural to engage patients in a discussion of their health care and convey my whole focus to them using the telephone. For a nurse who thrives on delivering value in patient care, and genuinely enjoys patient relationship management, this practice of ensuring good care transitions is vital to a health system where patients often feel lost and discouraged after a discharge from acute care.

\section{References}

1. Koloroutis M (2014) The therapeutic use of self: Developing three capacities for a more mindful practice. Creat Nurs 20: 77-85.

2. Dilwali PK (2013) From acute care to home care: The evolution of hospital responsibility and rationale for increased vertical integration. J Healthc Manag 58: 267-276.

3. King BJ, Gilmore-Bykovskyi AL, Roiland RA, Polnaszek BE, Bowers BJ, et al. (2013) The consequences of poor communication during transitions from hospital to skilled nursing facility: A qualitative study. J Am Geriatr Soc 61: 1095-1102.

4. Rennke S, Ranji SR (2015) Transitional care strategies from hospital to home: A review for the neurohospitalist. Neurohospitalist 5: 35-42.

5. Arbaje AI, Kansagara DL, Salanitro AH, Englander HL, Kripalani S, et al. (2014) Regardless of age: Incorporating principles from geriatric medicine to improve care transitions for patients with complex needs. J Gen Inter Med 29: 932-939. 
Citation: Pelkki R (2018) Reflection on Transitioning the Therapeutic Relationship from the Bedside to the Telephone. J Nurs Care 7: 447. doi: 10.4172/2167-1168.1000447

Page 3 of 3

6. Graham J, Gallagher R, Bothe J (2013) Nurses' discharge planning and risk assessment: Behaviours, understanding and barriers. J Clin Nurs 22 2338-2346.

7. Haas SA, Swan BA (2014) Developing the value proposition for the role of the registered nurse in care coordination and transition management in ambulatory care settings. Nurs Econ 32: 70-79.
8. Rollnick S, Miller WR, Butler CC (2008) Motivational interviewing in health care: Helping patients change behavior. The Guilford Press, Epub Edition, New York.

9. Swensen, S, Pugh, M, McMullan, C, Kabcenell, A (2013) High-impact leadership: Improve the health of populations and reduce costs. Institute for Healthcare Improvement. 